\title{
The chemical ecology of host-parasite interaction as a target of Varroa destructor control agents
}

\author{
Erika Plettner ${ }^{1}$, Nurit Eliash ${ }^{2}$, Nitin K. SingH ${ }^{2}$, Govardhana R. Pinnelli ${ }^{1}$, \\ Victoria SOROKER ${ }^{2}$
}

\author{
${ }^{1}$ Department of Chemistry, Simon Fraser University, 8888 University Dr., Burnaby, B.C. V5A 1S6, Canada \\ ${ }^{2}$ Department of Entomology, Institute of Plant Protection, Agricultural Research Organization, The Volcani Center, PO \\ Box 6 50250, Bet Dagan, Israel
}

Received 22 December 2015 - Revised 30 March 2016 - Accepted 17 May 2016

\begin{abstract}
Honey bees and their ectoparasite Varroa destructor communicate through chemical signals among themselves, but they also eavesdrop on each other's chemical cues. We summarize semiochemicals of honey bees and Varroa, and their roles in honey bee-Varroa interactions. We also give an overview of current Varroa control methods, which can be classified into three categories: (1) chemical control methods with acaricides, (2) biotechnical intervention, and (3) bee breeding programs. Widely used synthetic chemical acaricides are failing due to the emergence of resistant mites. Therefore, new methods are being sought for Varroa control, and methods that target the semiochemical interactions between bees and mites are among the candidates. We review our discovery of compounds that alter the host choice of Varroa mites (from nurse to forager) in laboratory tests. Any semiochemicalbased methods are still in the experimental stage and need validation in the field.
\end{abstract}

\section{Apis mellifera / Varroa destructor / mite control / chemical senses / semiochemical}

\section{INTRODUCTION}

Honey bees (Apis mellifera L.) are central to modern agricultural practices because they pollinate many crops, for which fruit set depends on insect pollination. Additionally, honey bee pollination improves quality and yield of many other crops that do not fully depend on insect pollination. Figure 1 depicts the number of plant categories (species or groups of species) that are raised for food in more than $4 \times 10^{6}$ tons/year, and the total amount produced in each category (Klein et al. 2007). Honey bees provide $~ 90 \%$ of insect pollination required in the production of these most prevalent food crops consumed by humans (Klein et al. 2007). The economic value of honey

Corresponding author: E. Plettner, plettner@sfu.ca Manuscript editor: Peter Rosenkranz bee pollination in food production has been estimated at $€ 138$ billion, and the surplus losses in human food crops if all insect pollinators were to disappear have been estimated at $€ 191-310$ billion (Gallai et al. 2009).

In recent years, bee populations have experienced large fluctuations and regional declines, and this has been problematic for the production of crops that require insect pollination, as well as for the sustainability of beekeeping businesses (Naug 2009; Le Conte et al. 2010; Rosenkranz et al. 2010; Moritz and Erler 2016). Losses of bee colonies have been attributed to various factors: mites, viral diseases (vectored by mites) (Le Conte et al. 2010; Rosenkranz et al. 2010; Kuster et al. 2014; Guzmán-Novoa et al. 2010), microsporidial parasites (Wolf et al. 2014), exposure to agrochemicals (Samson-Robert et al. 2014; SimonDelso et al. 2014), migratory beekeeping (Le Conte et al. 2010), very dense apiaries (Frey and Rosenkranz 2014), and changes in floral resources 

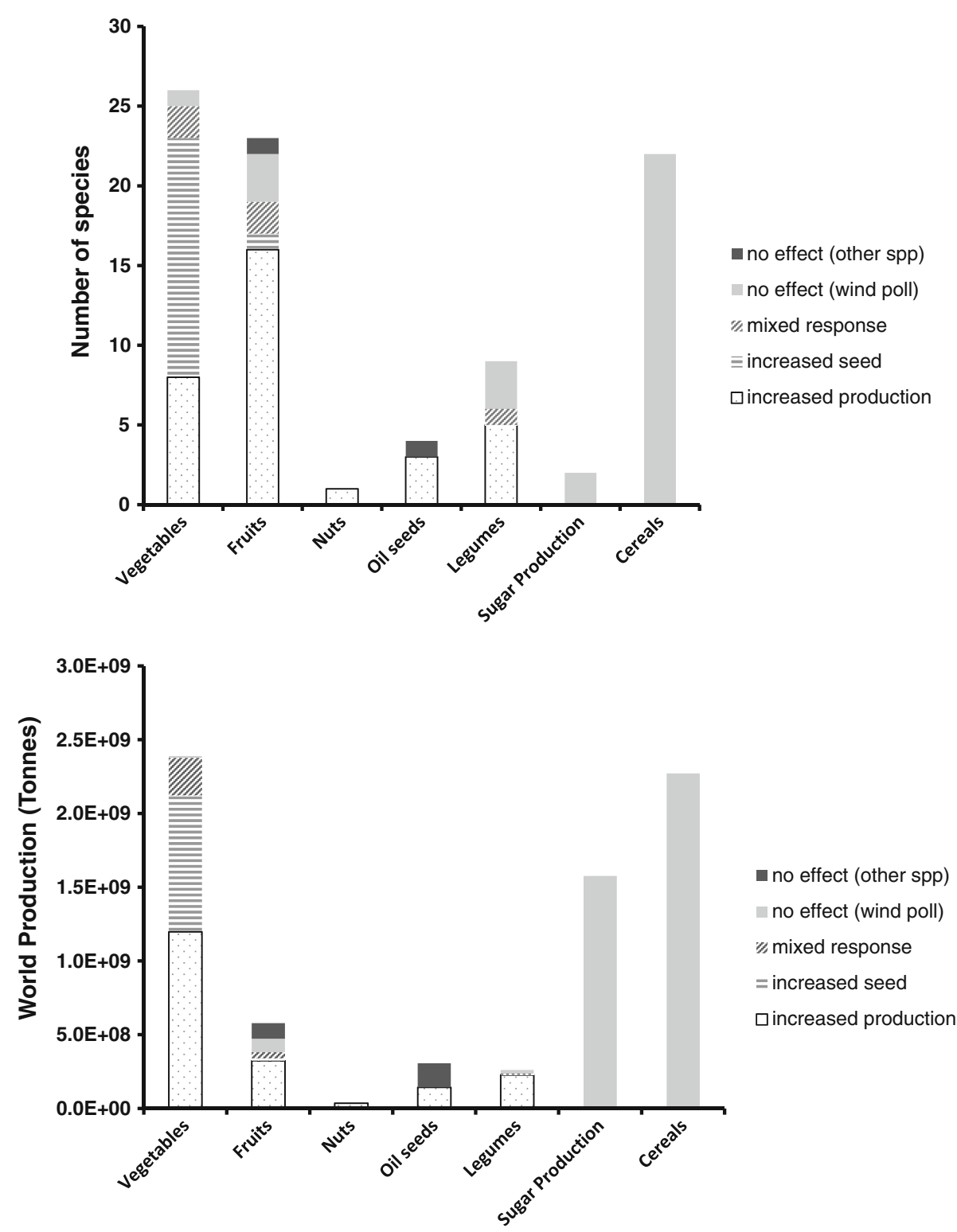

Figure 1. Contribution of insect pollination to the production of human food crops. The graphs were generated from data given in the appendices of reference 1. Shading (see legend) indicates the contribution of insect pollination: black = insect pollination has no effect but other animals are the pollinators; gray = wind pollination; diagonally hatched $=$ insect pollination has a mixed effect on both increased seed production and increased crop production; horizontally hatched $=$ insect pollination increases seed production; white dotted $=$ insect pollination increases production of the crop.

(Naug 2009; Donkersley et al. 2014; Sponsler and Johnson 2015). These factors are believed to be interdependent and to synergize in the losses of bee colonies. For example, viruses vectored by
Varroa appear to synergize with the mites themselves in bee immunosuppression and the development of increasingly virulent viral infection (Nazzi and Pennacchio 2014). 
The ectoparasitic mite Varroa destructor (Anderson and Trueman) is at the top of the list of risk factors for honey bee colonies worldwide, except Australia where the mite has not yet invaded. Varroa attacks honey bees and weakens them; if left untreated, a Varroa-infested colony usually withers and eventually dies. Varroa mites parasitize both adult bees and pupae: they reproduce in recently capped brood cells and emerge with the adult bee (see "Semiochemicals produced and detected by Varroa mites" section below). These two stages in the Varroa life cycle are known as the reproductive and phoretic stages, respectively. Varroa transmits Deformed Wing Virus (DWV) and Acute Bee Paralysis Virus (ABPV), among other viral diseases. DWV reduces the worker life span during overwintering, such that insufficient workers are available to build up the colony in the spring. ABPV kills the bees more quickly than DWV, thereby leading to more acute disease and faster colony losses (Francis et al. 2013; Kuster et al. 2014). Mite infestation, along with the transmitted viral diseases, has been shown to be the major cause of colony losses during overwintering in northern latitudes, e.g., in Canada (GuzmánNovoa et al. 2010).

Since Varroa mites switched from their original host, the Asian honey bee Apis cerana, to the European/African honey bee species, A. mellifera, various mite control methods have been implemented (Rosenkranz et al. 2010). These control methods can be divided into three groups: (1) chemical treatment, (2) biotechnical intervention, and (3) bee breeding. The most widely practiced control method in commercial apiaries is chemical treatment with miticidal compounds (see below). One problem with some of the most Varroa-effective agents used, such as the pyrethroid-fluvalinate, the formamidine-amitraz, or the organophosphate-coumaphos, is that the mites have developed resistance to these agents (see below, "Chemical control methods" section). Therefore, there is a worldwide effort to find new compounds and strategies for controlling or mitigating Varroa infestations in commercial honey bee colonies. Some of the new strategies being researched include (1) small inhibitory ribonucleic acid (RNAi) intervention, (2) Varroa pathogens, and (3) chemosensory mite disruption.
Honey bees and Varroa mites both depend on a myriad of chemical signals to communicate among their conspecifics and to sense the other species. Therefore, chemical communication is a good target for the development of new Varroa control tactics. Varroa mites have a specialized chemosensory organ on the forelegs, and bees have chemosensory structures (sensilla) on their antennae which they use to detect odors (see "Chemical senses of arthropods" section). In this article, we will summarize the known relevant chemical communication vocabulary of honey bees and Varroa mites, and how Varroa mites mimic and eavesdrop on honey bee signals ("Semiochemicals and chemoreception of honey bees and Varroa mites" section). We will start with an overview of the various control methods and tactics employed or being developed to control Varroa infestation in colonies ("Varroa control methods and the need for new approaches" section), to provide a sense of where semiochemical methods might fit into an integrated pest management scheme for Varroa.

\section{VARROA CONTROL METHODS AND THE NEED FOR NEW APPROACHES}

\subsection{Chemical control methods}

Chemical intervention can be divided into three subgroups: (1) synthetic acaricides, (2) natural product acaricides, and (3) organic acids. All chemical methods aim to reduce mite populations by selectively killing mites.

Synthetic acaricides, such as the pyrethroid fluvalinate 1 (Figure 2), have been used for a long time because they are effective and relatively selective toward mites (i.e., have a low toxicity toward bees) (Lindberg et al. 2000). Due to widespread resistance of the mites against fluvalinate (González-Cabrera et al. 2013), other synthetic acaricides (amitraz 2, a formamidine, and coumaphos 3, an organophosphate) have been used. Resistance against amitraz (Elzen et al. 2000) and coumaphos (Maggi et al. 2009) has also been documented, though amitraz is still used successfully in many places. A major disadvantage of synthetic acaricides is that they are hydrophobic 
<smiles>CC(C)[C@H](Nc1ccc(C(F)(F)F)cc1Cl)C(=O)O[C@H](C#N)c1cccc(Oc2ccccc2)c1</smiles><smiles>Cc1ccc(/N=C/N(C)/C=N/c2ccc(C)cc2C)c(C)c1</smiles>
2<smiles>CCOP(=S)(OCC)Oc1ccc2c(C)c(Cl)c(=O)oc2c1</smiles><smiles>Cc1ccc(C(C)C)c(O)c1</smiles>

4<smiles>[R]C(=O)C1=C(O)C(CC=C(C)C)=C(O)[C@@](O)(CC=C(C)C)C1=O</smiles>

$5 a$

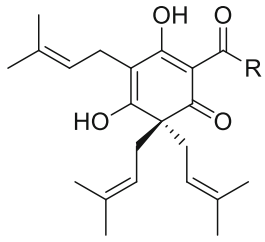

$5 b$
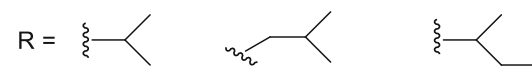

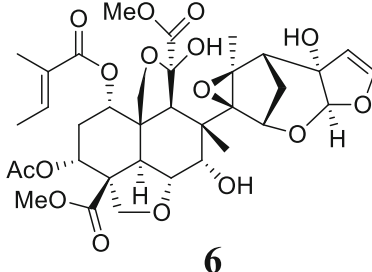

6

Figure 2. Structures of compounds used to control Varroa mites.

and accumulate in wax, leading to accelerated development of resistance, as well as sub-lethal effects on bees (due to continuous low-level exposure) and contamination of hive products (Frost et al. 2013; Hillier et al. 2013).

The natural acaricide thymol $\mathbf{4}$ is widely used in beekeeping, in various formulations (Imdorf et al. 1999; Lindberg et al. 2000; Le Conte et al. 2010). The compound is selective for mites, but irritates the bees (by binding to dopamine receptors) and can affect the taste of honey if used in high doses (Mondet et al. 2011). Lately, symptoms for resistance to thymol have also been reported (Pietropaoli et al. 2015). Hops extract, which contains humulones $\mathbf{5 a}$ and lupulones $\mathbf{5 b}$, is another natural acaricide that is useful in the shipment of bees and establishment of new colonies in the spring (DeGrandiHoffman et al. 2012, 2014). Neem oil, which contains many limonoids such as azadirachtin A 6, has been tested for Varroa control. Neem causes decreases in mite numbers (Lindberg et al. 2000; Melathopoulos et al. 2000), but it also causes increased queen and brood mortality (Naumann and Isman 1996). Therefore, neem is not used commercially to manage Varroa .

Organic acids (formic 7 and oxalic acids 8 ) are widely used for spring and fall treatments against Varroa (Rademacher and Harz 2006; Calderone 2010; Giovenazzo and Dubreuil 2011). They do not accumulate in wax while still permeating the hive. Formic acid being much more volatile than oxalic is apparently able to penetrate the brood capping and thus affect both reproducing mites in capped cells and phoretic mites (which parasitize adult bees), but causes higher worker and queen mortality than oxalic acid (Giovenazzo and Dubreuil 2011). Although resistance to most natural acaricides or organic acids has not been reported, the potential for resistance evolution exists because all of these compounds reduce mite populations by acaricidal action.

\subsection{Biotechnical intervention}

The most widely practiced biotechnical intervention is drone brood removal. It is based mainly on two facts: (1) drone brood is $\sim 10-12$ times more attractive to female Varroa mites than worker brood (Boot 1994; Rosenkranz et al. 2010), likely because drone brood are larger than worker brood and produce more of the Varroa-arresting odors (see below, "Semiochemicals of honey bees" section, fatty acid esters $16 \mathbf{a}, \mathbf{1 6 b}$, 18a-18d ) just prior to capping, and (2) its development is longer than that of workers allowing production of more female mites per cell. Combs that encourage the building of drone cells are installed in the colony; the queen is allowed to lay unfertilized eggs and drone brood is established. If removal of the trap comb is timed correctly, mite numbers can be kept low by this approach (Maul et al. 1988; Calis et al. 1999; Calderone 
2005; Wantuch and Tarpy 2009). The disadvantages of the method are as follows: (1) it is labor intensive, (2) it needs to be timed with drone rearing in the spring, (3) it leads to loss of brood, and (4) the mite population can rebound (Maul et al. 1988).

Brood interruption by queen confinement is another method of decreasing the total amount of brood that is available for Varroa females to reproduce. The queen is caged on the comb during the late summer, for approximately 1 month. During this time, less and less brood becomes available for Varroa to reproduce (Lodesani et al. 2014). Moreover, in the absence of capped brood, phoretic mites can be more efficiently treated by compounds such as oxalic acid $\mathbf{8}$. The disadvantages of the method are as follows: (1) it is labor intensive, (2) it needs to be timed not to interfere with honey production, and (3) it may cause queen loss.

\subsection{Bee breeding}

Bee breeding to increase Varroa tolerance is a promising strategy for sustainable control of Varroa infestation. Two approaches are used: (1) breeding bees known to have survived Varroa infestation for longer than a decade without intervention (Locke et al. 2012; Rinderer et al. 2014a, b), and (2) selecting bee lines that exhibit Varroa-specific hygienic (VSH) behavior (Tsuruda et al. 2012; Danka et al. 2013; Nicodemo et al. 2013; Rinderer et al. 2014a, b). VSH bee lines have been shown to remove significantly more Varroainfected pupae than control lines. This removal seemed dependent on a threshold signal accumulating up to 5 days post-capping, generally from Varroa progeny developing in a cell (Harris 2015). Colonies bred for hygienic behavior show suppression of mite reproduction (SMR) and have been shown to contain significantly fewer phoretic and reproducing mites than the wildtype colonies (Ibrahim et al. 2007; de Guzman et al. 2015). It is important to note that VSH may be only one of several behavioral traits in colonies that suppress mite reproduction and, therefore, are more resistant to Varroa (see "Interaction of Varroa with A. cerana and Africanized honey bees (AHB)" section).

Grooming behavior of bees is another trait that is being explored in breeding programs (Currie and Tahmasbi 2008). Workers groom phoretic mites from their bodies, often damaging the mites in the process and causing them to fall. A recent linkage map revealed some candidate genes (many of them central nervous system genes) associated with grooming behavior (Arechavaleta-Velasco et al. 2012).

\section{SEMIOCHEMICALS AND CHEMO- RECEPTION OF HONEY BEES AND VARROA MITES}

\subsection{Semiochemicals of honey bees}

In a honey bee colony, chemical cues are the principal mode of communication and social coherence (Keeling et al. 2004).

The queen produces a series of $\omega-1$ functionalized 10-carbon fatty acids 9, 10 (Figure 3) (Plettner et al. 1996), aromatic compounds 11 13, hexadecane-1-ol 14, linoleic acid 15, and methyl oleate 16a as part of her queen pheromone (Slessor et al. 1988; Keeling et al. 2003). Middleaged workers produce a series of $\omega$ functionalized 10-carbon fatty acids $\mathbf{1 7}$ that are added to brood food and royal jelly. Older brood produce a blend of methyl and ethyl esters 18 that signal to nurse bees that the brood is ready for capping (Le Conte et al. 2006), whereas young brood produce $(E)$ - $\beta$-ocimene 19 to stimulate feeding from nurses (Maisonnasse et al. 2009). Foragers produce ethyl oleate $\mathbf{1 6 b}$, a signal that (together with old brood pheromone, 18 ) delays the transition of nurses into foragers (Alaux et al. 2009; Castillo et al. 2011). Foragers also emit a monoterpene blend pheromone (Nasonov, pheromone, of which 20a and 20b are components) at the hive entrance to attract foragers homing in (Williams et al. 1981). The sting glands of foragers contain an alarm pheromone (isopentyl acetate 21, 2-nonanol 22, and 2-heptanone 23; Figure 2), which attracts other bees and increases their aggressiveness (Allan et al. 1987).

\subsection{Semiochemicals produced and detected by Varroa mites}

Varroa mites develop from eggs laid by the foundress (mated female) that entered a worker or drone brood cell shortly before its capping. Once a brood cell has been capped, the FA ester blend emitted by the pupa changes: ethyl esters 18c, $\mathbf{1 8 d}, \mathbf{1 8 f}, \mathbf{1 8 h}$, and $\mathbf{1 6 b}$ nearly disappear, whereas three methyl esters $\mathbf{1 8 a}, \mathbf{1 8 b}$, and $\mathbf{1 6 a}$ remain 


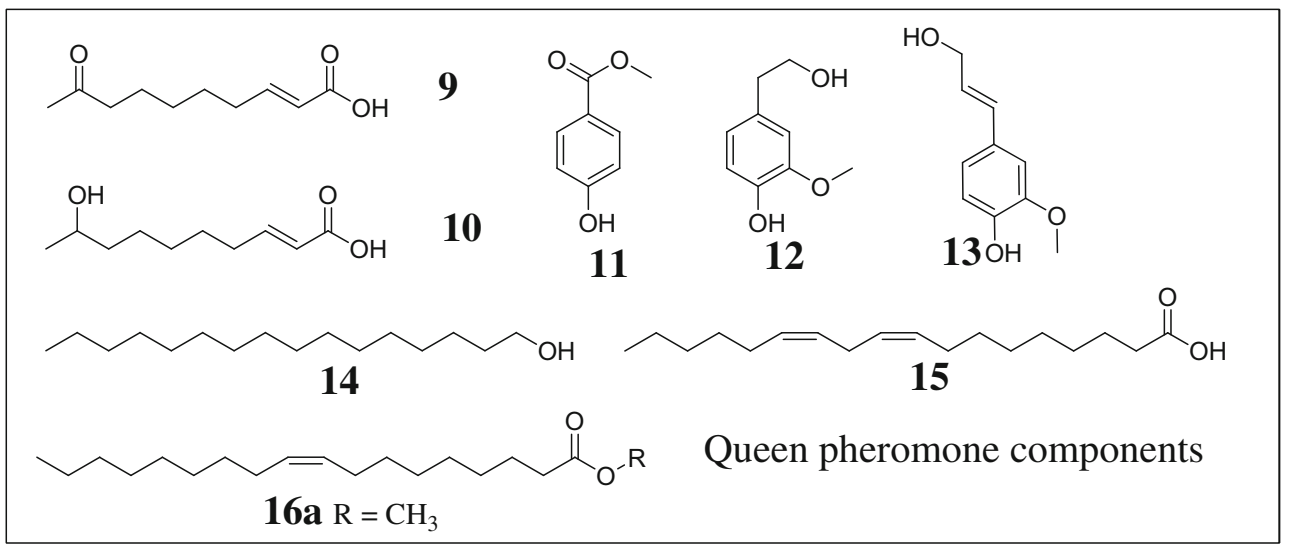

(19)<smiles>CCCC[C@H](O)C(=O)O</smiles>

Acid in brood food attractive to Varroa females. 24 The stereochemistry at C-2 is not known.

Figure 3. Selected compounds found in various honey bee pheromones.

high; these have been shown to trigger reproductive maturation of newly emerged Varroa daughters (Frey et al. 2013) by vitellogenin induction (Cabrera Cordon et al. 2013). However, these methyl esters cause artificially introduced phoretic

\section{Forager-specific Varroa deterrent}

Varroa females to resorb their eggs and forego reproduction, likely as a signal that the pupa in the cell is too far developed for the next generation of mites to complete their development prior to bee emergence (Frey et al. 2013). Thus, Varroa 
reproduction is timed very delicately with the signals from the bee brood.

The first mite to hatch is a male; all that follow (three to five) are females (Garrido and Rosenkranz 2003). The volatile signal in the capped cell, which contains $18 \mathrm{a}, \mathbf{1 8 b}$, and 16a, also ensures that the first offspring of the foundress is male and, therefore, that the daughters mate and will be fertile (Garrido and Rosenkranz 2003). The young females emit a sex pheromone that attracts the male and elicits courtship and mating behavior (Ziegelmann et al. 2013a, b). This pheromone consists of three fatty acids (palmitic, stearic, and oleic) and their respective ethyl esters 18c, 18d, and 16b. Older females no longer make this pheromone, so mating has to occur within a short window of time (Ziegelmann et al. 2013a).

After mating, the female mites continue their development, synchronized with that of the bee pupa. When the bee emerges, the female mites cling to the bee and become phoretic. During the phoretic phase, Varroa females parasitize adult worker bees, mainly nurses. Phoretic Varroa females detect and respond to several compounds produced by bees. The mites are arrested (i.e., stop moving about) by a blend of fatty acid esters 18a, 18c , and 18e from old bee larvae (Calderone and Lin 2001) and by aliphatic alcohols and aldehydes of honey bee cocoons (Donzé et al. 1998). The mites are deterred and repelled by geraniol and nerolic acid 20a, 20b (Pernal et al. 2005), both components of the Nasonov pheromone which is produced in larger quantities by foragers than by nurses (Figure 3), and this may be one reason why phoretic Varroa mites prefer nurse bees over foragers. Varroa females are also deterred by the $\omega$-functionalized fatty acids from royal jelly 17 (Drijfhout et al. 2005). Brood food contains a volatile compound, 2hydroxyhexanoic acid 24 (enantiomer not known), that is attractive to phoretic Varroa females (Nazzi et al. 2004). Finally, foragers appear to have higher titers of (Z)-8-heptadecene $\mathbf{2 5}$ in their cuticular hydrocarbon blend than nurses, and this compound has been also shown to deter Varroa females (Piccolo et al. 2010).

Supporting the importance of chemoreception in Varroa mites as they enter brood cells and switch from phoretic to reproductive, a recent study has found that the pheromone receptor transcription factor like (PRTF) is expressed much more abundantly in the forelegs of phoretic mites than of reproductive ones (Singh et al. 2016). Phoretic mites with experimentally reduced levels of PRTF (through RNAi) had weaker electrotarsogram responses to bee head space and took longer to find a host, but had induced vitellogenin levels (Singh et al. 2016).

It is important to note that several compounds (e.g., fatty acids or esters) have different roles or meanings in different contexts in the hive. Adding these multifunctional semiochemicals to a colony, e.g., to affect a particular behavior of Varroa or of the bees, may cause side effects elsewhere in the colony. This is why we decided to test synthetic odorants with Varroa and bees (see below, "Synthetic odors that affect mite behavior" section).

\subsection{Odors produced by diseased brood}

Chemosensory detection of diseased brood plays an important role in hygienic behavior. For example, in one study, specific odor signatures of chalkbrood-infested brood were identified as phenethyl acetate 26, phenyl ethanol 27, and benzyl alcohol 28 (Figure 4). Hygienic honey bee colonies uncapped cells that contained dummies impregnated with $\mathbf{2 6}-\mathbf{2 8}$ significantly faster than cells with control dummies (Swanson et al. 2009). Similar odors from Varroa-infested brood have not yet been identified, but probably

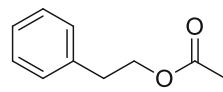

26

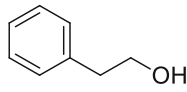

27

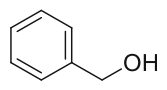

28

Figure 4. Structures of compounds emitted by chalkbrood-infested bee larvae that induce hygienic behavior in worker bees. 
exist as VSH behavior, and Varroa resistant lines show differential expression of genes that are likely involved in chemoreception (Parker et al. 2012; Guarna et al. 2015).

\subsection{Synthetic odors that affect mite behavior}

Our research has led to the identification of various synthetic compounds that affect the behavior of Varroa mites. Various aromatic and alicyclic ethers 29-31 (Figure 5) were screened by both electrotarsogram recordings from phoretic Varroa forelegs and behavioral assays, in which a phoretic Varroa female was left to choose between a freshly freeze-killed nurse and forager. Normally, phoretic Varroa females choose a nurse over a forager, and this preference matches the fact that a nurse bee is likely to take them to a brood cell where the mite can start the next cycle of reproduction. We found compounds that reverse this choice. These compounds also cause a long-term inhibition of the detection of nurse headspace odor in electrotarsogram tests. Compounds 29-31 did not affect the frequency with which a mite chose a nurse or forager bee host (Eliash et al. 2014). Chiral compounds 30 and 31 were active as racemates; the activity of individual enantiomers is being explored currently.

We have also found that $N, N$-diethyl-3methylbenzamide 32 (DEET) decreases the frequency with which phoretic mites find a host bee in laboratory bioassays, but it does not alter the host choice the way the ethers 29-31 do (Singh et al. 2014). Thus, DEET acts as a host finding deterrent in laboratory bioassays, whereas the ethers 29-31 alter the host choice of phoretic mites. Electrophysiologically, DEET caused long-term inhibition of Varroa foreleg responses to nurse bee headspace, whereas it is sensed by bees, and it caused transient (short-term) inhibition of honey bee antennal responses to queen bee head space. Behaviorally, DEET did not visibly affect the interaction of workers with the queen (Singh et al. 2014), even though it has been known as an effective bee repellent (Schroeder et al. 2007). On the other hand, cy $\{4,1\} \mathbf{3 1}$ showed long-term inhibition of Varroa foreleg responses to both nurse bee headspace and $(E)$ $\beta$-ocimene, and it showed a short-term enhancement of honey bee antennae to $(E)-\beta$-ocimene (Singh et al. 2015). Its effect on bee behavior remains to be tested. The effect of all Varroa chemosensory disruptive compounds remains to be evaluated at colony level.

\subsection{Chemical senses of arthropods}

Bees and mites detect the chemical signals described earlier through gustation and olfaction. Both chemical senses are located in sensilla, external cuticular structures that are innervated by sensory neurons. Olfactory sensilla are located mostly on appendages such as antennae, whereas gustatory sensilla are located on the mouth parts and are double-walled with a single pore at the top (Ryan 2002). Some olfactory sensilla are singlewalled and multiporous (e.g., s. basiconica, s. placodea); others are double-walled (s. coeloconica) (Ryan 2002). Bees also have sensilla placodea on their antennae; these single-walled, multiporous plate-like structures are innervated by 5-35 olfactory receptor neurons (ORNs) (Akers and Getz 1992). Regardless of sensillum type, the dendritic end of each ORN interacts with odorants, and the axon of each ORN projects to a particular region of the antennal lobe in the brain, a glomerulus. ORNs tuned to the same odorants have their axons converge in the same glomerulus (Kelber et al. 2006).

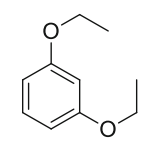

$\mathbf{3 b}\{2,2\} \mathbf{2 9}$

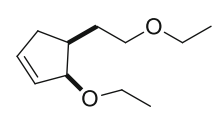

cy $\{2,2\} \mathbf{3 0}$

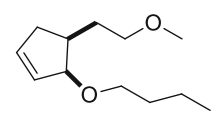

cy $\{4,1\} \mathbf{3 1}$

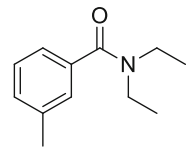

DEET 32

Figure 5. Compounds discovered that disrupt host choice or decrease the frequency of host choice in phoretic Varroa females. 
Mites do not have antennae; instead, they use their front pair of legs as chemosensory organs. The front legs contain a pit organ that has nine olfactory sensilla, shaped like sensilla basiconica (Dillier et al. 2006; Eliash 2012; Häußermann et al. 2015). Based on electrophysiological recordings, the mite's front legs clearly respond to volatile stimuli (Eliash et al. 2014; Singh et al. 2014).

Chemosensory sensilla contain several proteins that interact with chemical signals. The chemoreceptors on the neuronal dendrites are the sensors of chemical signals. There are two types of odorant receptors known for arthropods: (1) odorant receptors (ORs) with seven membrane-spanning regions and a co-receptor (ORCO) with which ORs pair (Wanner et al. 2007; Wanner and Robertson 2010), and (2) variant ionotropic receptors (IRs) that are ion channels and distant relatives of the glutamate receptors (iGluRs) (Croset et al. 2010). Each OR is paired with a conserved co-receptor that serves as chaperone and probably forms a ligand-gated ion channel with the receptor, a mechanism distinct from that of vertebrate G-protein coupled receptors (Wanner and Robertson 2010). To date, the OR/ORCO system has only been detected in insects, including honey bees (Wanner et al. 2007; Wanner and Robertson 2010). IRs do not appear to be paired with any coreceptor, but have to form multimeric structures to function as ligand-gated ion channels (Croset et al. 2010). Arthropods, nematodes, and mollusks have IRs, and insects have an expanded set of divergent antennal IRs (Croset et al. 2010). Recently, IR40a in Drosophila melanogaster was identified as the main target site of DEET (Kain et al. 2013), and crustaceans have been found to have IRs as their only olfactory receptors instead of OR/ORCO systems (Corey et al. 2013). Mites, therefore, will likely have some chemosensory IRs. Genomic data for Varroa are a valuable repository for the identification of chemosensory genes in these mites (Cornman et al. 2010).

The dendrite of an olfactory sensory neuron responds to odorant activation of the chemoreceptor (either OR or IR) by depolarizing. This initial depolarization is followed by neuronal spiking, a response mediated by voltage-gated channels. Voltage-gated cation channels that are distinct from the $\mathrm{Na}^{+}$channels in the central nervous system have been detected in insect sensilla (Zufall et al. 1991). Surrounding the dendrites of chemosensory neurons is the lymph, an electrolyte solution rich in fatty acids and odorantbinding proteins (OBPs) or chemosensoryspecific proteins (CSPs) (Honson et al. 2005). The function of OBPs is not well understood; it is believed that these proteins aid in diffusion of odorants through the lymph and also act as kinetic traps to prevent adaptation of the ORN (Gong et al. 2009). It is interesting to note that hygienic worker bees (bred based on the freeze-killed brood removal bioassay) detect and remove diseased larvae apparently by identifying specific odors from diseased brood (Swanson et al. 2009). Recent proteomic analyses have revealed that two bee OBPs (16 and 18) are more abundantly expressed in hygienic bee lines than in wild-type lines (Guarna et al. 2015).

Neurotransmitters, particularly octopamine, also play a role in controlling olfactory processes in insects. For example, hygienic bee lines were found to have more octopamine-containing neuronal clusters in the brain and these stained more intensely than those from wild-type lines (Spivak et al. 2003). Hygienic bees responded more strongly and with lower thresholds to diseased brood odorants (see below), and this response was diminished by an octopamine antagonist (Spivak et al. 2003). The differences in chemosensory mechanisms between bees and mites might be useful in the development of agents that alter the behavior of Varroa, while not affecting bee behavior, or that improve the detection of Varroa by bees.

\subsection{Interaction of Varroa with A. cerana and Africanized honey bees (AHB)}

A. cerana, the original host of Varroa mites, is more resistant to mite infestation than A. mellifera (Tewarson et al. 1992). Three reasons have been suggested for this resistance: (1) A. cerana workers groom more (both themselves and other workers), particularly if the mite is from another colony. (2) The mites reproduce only in drone brood; mites that emerge from worker brood are generally sterile because A. cerana workers have a shorter pupal development compared to 
A. mellifera workers and their brood cells are smaller. (3) There appears to be more Varroatriggered hygienic behavior in A. cerana than in A. mellifera; workers uncap cells with infested pupae and remove either the whole pupa with mites or the foundress, particularly if she is from another colony (Tewarson et al. 1992). The hygienic behavior appears to be elicited by the odor of the mites (Rosenkranz et al. 1993). A. cerana is similar to A. mellifera in its $\omega$ - and $\omega$-1 functionalized fatty acid profile (Plettner et al. 1997); however, its brood-associated pheromones are not known. Given that the interaction between Varroa and Apis is subtly timed by the ontogeny of various bee semiochemicals, the pheromones of A. cerana, as well as A. cerana's ability to detect mite odors, should be explored further.

Africanized honey bees (AHB) are derived from A. mellifera scutellata taken to Brazil, where it has been noted that AHB are also more Varroa resistant than the European races of $A$. mellifera (EHB) (Calderón et al. 2010). As in A. cerana, mite reproduction on AHB is less successful than on EHB. AHB groom more, exhibit more hygienic behavior towards mite-infested nestmates, and they have shorter development times and smaller cells for worker brood than EHB (Calderón et al. 2010). Thus, AHB colonies have fewer fertile mites. AHB have similar mandibular gland semiochemicals to EHB (Plettner et al. 1993; Pankiw et al. 1996), but the subtleties of their other pheromones or of odors that elicit hygienic behaviors are not known. Thus, these AHB semiochemicals and their cognate OBPs, ORs, or IRs (see "Chemical senses of arthropods" section) should be studied and compared to EHB as potential molecular markers of desirable Varroa resistance traits in breeding programs.

\section{NEW VARROA CONTROL AVENUES BEING RESEARCHED}

\subsection{Small inhibitory ribonucleic acid (RNAi)}

RNAi involves the treatment of honey bees with small inhibitory, double-stranded (ds) RNA sequences that target Varroa-specific processes and do not affect the bees. For example, feeding of bees with dsRNA against DWV caused the virus titer to decrease significantly and adult bee survival to increase significantly (Desai et al. 2012). In another example, mixtures of dsRNAs against multiple Varroa-specific genes were fed to bees and shown to be transferred horizontally to Varroa. One of these mixtures was very effective in reducing Varroa population by silencing the expression of selected genes in the mites (Garbian et al. 2012). The gene of a glutathione $S$-transferase (GST, a detoxification enzyme that couples electrophilic centers on hydrophobic substances to a hydrophilic peptide to increase excretion) has been successfully downregulated in Varroa through treatment of mites with RNAi. However, this GST-specific RNAi was not tested in bee colonies (Campbell et al. 2010).

Specific receptors or CSPs in the Varroa mites could be promising targets for RNAi intervention. For example, targeting the/a receptor responsible for detecting L5 larvae might result in a decrease in successful cell invasion by phoretic mites and, thus, a lower reproductive rate. Alternatively, targeting the/a receptor responsible for a foundress' decision to lay eggs may disrupt the delicate timing of this process and thereby also lower reproductive rates.

One challenge with this technique is that high doses of the dsRNA are needed, as RNA hydrolyzes easily while in the food or in the digestive tract of the bees.

\subsection{Varroa pathogens}

A recent survey of bacterial pathogens associated with phoretic Varroa females has revealed nine strains of Bacillus thuringiensis that cause high mortality to Varroa but do not affect the bees (Alquisira-Ramírez et al. 2014). Furthermore, several searches for entomopathogenic fungi have identified strains of Metarhizium anisopliae, Beauveria bassiana, and Clonostachys rosea that kill Varroa mites, thereby causing mite drops and decreased mite reproduction (Hamiduzzaman et al. 2012; Meikle et al. 2012; Pirali-Kheirabadi et al. 2013). These fungi also infect the bees, thereby triggering strong immune responses that seem to counteract the Varroa-induced immunosuppression (Hamiduzzaman et al. 2012). Some 
challenges of entomopathogenic fungi include the formulation of fungal conidia preparations, the formation of potentially harmful mycotoxins upon fungal infection, and the mixed effects of bees (Meikle et al. 2012).

\subsection{Chemosensory mite disruption}

Recently, the mite sex pheromone has been identified and shown to cause mating disruption if applied to wax comb. Mating disruption and decreased Varroa reproduction have been observed by addition of oleic acid to combs, which caused reduced spermatozoa loads in Varroa females due to decreased mating (Ziegelmann and Rosenkranz 2014) or mistimed introduction of phoretic Varroa mites to capped brood cells (Frey et al. 2013). The challenge with the mite pheromone is that it consists of compounds that are also used for signaling by the bees; its widespread application in the hive may cause side effects to the bees.

Our recently discovered compounds 29-31 could be released in a colony to get phoretic mites to move from nurses to foragers and, therefore, be carried away from the brood thus exposing the Varroa to grooming bees and/or to soft acaricidal agents (Eliash et al. 2014). One potential problem with this strategy could be more drifting of mites riding on foragers between colonies in dense apiaries.

\section{CONCLUSIONS}

Acaricide-based Varroa control methods alone are not sustainable because of the rapid development of resistant mite populations and sub-lethal effects on bees. Therefore, new approaches for Varroa control are needed. Here, we have given an overview of the main chemical signals emitted and perceived by bees and mites. We have also summarized commonly used methods as well as new promising strategies for Varroa control being researched. Many of these old and new methods may be suitable for integrated Varroa management. For example, biotechnical control methods and organic acids have already been explored in combination (Lodesani et al. 2014).
Chemosensory methods likely will be implemented alongside other methods to achieve synergistic control. For example, our compounds 2931 could be explored alongside other strategies, such as organic acids, VSH bees, and RNAi or biotechnical intervention, as part of integrated Varroa management.

L'écologie chimique de I'intéraction hôte-parasite comme cible des agents de lutte contre Varroa destructor

Apis mellifera / Acari / lutte anti-parasite / sens chimiques / médiateurs chimiques

Die chemische Ökologie der Wirt-Parasit-Interaktionen als eine Möglichkeit der Bekämpfung von Varroa destructor

Apis mellifera / Varroa destructor / Varroabekämpfung / Chemische Sinneswahrnehmung / Pheromone

\section{REFERENCES}

Akers, R.P., Getz, W.M. (1992) A test of identified response classes among olfactory receptor neurons in the honeybee worker. Chem. Senses 17, 191-209

Alaux, C., Le Conte, Y., Adams, H.A., Rodriguez-Zas, S., Grozinger, C.M., et al. (2009) Regulation of brain gene expression in honey bees by brood pheromone. Genes Brain Behav. 8, 309-319

Allan, S.A., Slessor, K.N., Winston, M.L., King, G.G.S. (1987) The influence of age and task specialization on the production and perception of honey bee pheromones. J. Insect Physiol. 33, 917-922

Alquisira-Ramírez, E.V., Paredes-Gonzalez, J.R., Hernández-Velásquez, V.M., Ramírez-Trujillo, J.A., Peña-Chora, G. (2014) In vitro susceptibility of Varroa destructor and Apis mellifera to native strains of Bacillus thuringiensis. Apidologie 45, 707-718

Arechavaleta-Velasco, M.E., Alcala-Escamilla, K., RoblesRios, C., Tsuruda, J.M., Hunt, G.J. (2012) Fine-scale linkage mapping reveals a small set of candidate genes influencing honey bee grooming behavior in response to Varroa mites. PLoS One 7 (11), e47269

Boot, W.J. (1994) Methyl palmitate does not elicit invasion of honeybee brood cells by Varroa mites. Exp. Appl. Acarol. 18, 587-592

Cabrera Cordon, A.R., Shirk, P.D., Duehl, A.J., Evans, J.D., Teal, P.E.A. (2013) Variable induction of vitellogenin genes in the varroa mite, Varroa destructor (Anderson \& Trueman), by the honeybee, Apis 
mellifera L, host and its environment. Insect Mol. Biol. 22, 88-103

Calderón, R.A., van Veen, J.W., Sommeijer, M.J., Sanchez, L.A. (2010) Reproductive biology of Varroa destructor in Africanized honey bees (Apis mellifera). Exp. Appl. Acarol. 50, 281-297

Calderone, N.W. (2005) Evaluation of drone brood removal for management of Varroa destructor (Acari: Varroidae) in colonies of Apis mellifera (Hymenoptera: Apidae) in the northeastern United States. J. Econ. Entomol. 98, 645-650

Calderone, N.W. (2010) Evaluation of Mite-Away-IITM for fall control of Varroa destructor (Acari: Varroidae) in colonies of the honey bee Apis mellifera (Hymenoptera: Apidae) in the northeastern USA. Exp. Appl. Acarol. 50, 123-132

Calderone, N.W., Lin, S. (2001) Behavioural responses of Varroa destructor (Acari: Varroidae) to extracts of larvae, cocoons and brood food of worker and drone honey bees, Apis mellifera (Hymenoptera: Apidae). Physiol. Entomol. 26, 341-350

Calis, J.N.M., Boot, W.J., Beetsma, J. (1999) Model evaluation of methods for Varroa jacobsoni mite control based on trapping in honey bee brood. Apidologie 30, 197-207

Campbell, E.M., Budge, G.E., Bowman, A.S. (2010) Geneknockdown in the honey bee mite Varroa destructor by a non-invasive approach: studies on a glutathione Stransferase. Parasite Vectors 3, 73-82

Castillo, C., Chen, H., Graves, C., Maisonnasse, A., LeConte, Y., Plettner, E. (2011) Biosynthesis of ethyl oleate, a primer pheromone in the honey bee (Apis mellifera L). Insect Biochem. Mol. Biol. 42 , 404-416

Corey, E.A., Bobkov, Y., Ukhanov, K., Ache, B.W. (2013) Ionotropic crustacean olfactory receptors. PLoS One $8(4)$, e 60551

Cornman, R.S., Schatz, M.C., Johnston, J.S., Chen, Y.-P., Pettis, J., Hunt, G., et al. (2010) Genomic survey of the ectoparasitic mite Varroa destructor, a major pest of the honey bee Apis mellifera. BMC Genomics 11, 602-617

Croset, V., Rytz, R., Cummins, S.F., Budd, A., Brawand, D., Kaessmann, H., et al. (2010) Ancient protostome origin of chemosensory ionotropic glutamate receptors and the evolution of insect taste and olfaction. PLoS Genet. 6(8), e1001064

Currie, R.W., Tahmasbi, G.H. (2008) The ability of high- and low-grooming lines of honey bees to remove the parasitic mite Varroa destructor is affected by environmental conditions. Can. J. Zool. 86, 1059-1067

Danka, R.G., Harris, J.W., Villa, J.D., Dodds, G.E. (2013) Varying congruence of hygienic responses to Varroa destructor and freeze-killed brood among different types of honeybees. Apidologie 44, 447-457

de Guzman, L.I., Rinderer, T.E., Frake, A.M., Kirrane, M.J. (2015) Brood removal influences fall of Varroa destructor in honey bee colonies. J. Apic. Res. 54 (3), 216-225
DeGrandi-Hoffman, G., Ahumada, F., Probasco, G., Schantz, L. (2012) The effects of beta acids from hops (Humulus lupulos ) on mortality of Varroa destructor (Acari: Varroidae). Exp. Appl. Acarol. 58, 407-421

DeGrandi-Hoffman, G., Ahumada, F., Curry, R., Probasco, G., Schantz, L. (2014) Population growth of Varroa destructor (Acari: Varroidae) in commercial honey bee colonies treated with beta plant acids. Exp. Appl. Acarol. 64, 171-186

Desai, S.D., Eu, Y.-J., Whynard, S., Currie, R.W. (2012) Reduction in deformed wing virus infection in larval and adult honey bees (Apis mellifera L.) by double-stranded RNA ingestion. Insect Mol Biol 21, 446-455

Dillier, F.-X., Fluri, P., Imdorf, A. (2006) Review of the orientation behaviour in the bee parasitic mite Varroa destructor: sensory equipment and cell invasion behaviour. Rev. Suisse Zool. 113, 857-877

Donkersley, P., Rhodes, G., Pickup, R.W., Jones, K.C., Wilson, K. (2014) Honeybee nutrition is linked to landscape composition. Ecol. Evol. 4, 4195-4206

Donzé, G., Schnyder-Candrian, S., Bogdanov, S., Diehl, P.-A., Guerin, P.M., et al. (1998) Aliphatic alcohols and aldehydes of the honey bee cocoon induce arrestment behavior in Varroa jacobsoni (Acari: Mesostigmata), and ectoparasite of Apis mellifera. Arch. Insect Biochem. Physiol. 37, 129-45

Drijfhout, F.P., Kochansky, J., Lin, S., Calderone, N.W. (2005) Components of honeybee royal jelly as deterrents of the parasitic Varroa mite, Varroa destructor. J. Chem. Ecol. 31 , 1747-1764

Eliash, N. (2012) Learning and disrupting the chemical communication of Varroa destructor Anderson and Trueman. Hebrew University, Jerusalem

Eliash, N., Singh, N.K., Kamer, Y., Pinnelli, G.R., Plettner, E., Soroker, V. (2014) Can we disrupt the sensing of honey bees by the bee parasite Varroa destructor? PLoS One 9 (9), e106889

Elzen, P.J., Baxter, J.R., Spivak, M., Wilson, W.T. (2000) Control of Varroa jacobsoni Oud. resistant to fluvalinate and amitraz using coumaphos. Apidologie 31, 437-441

Francis, R.M., Nielsen, S.L., Kryger, P. (2013) Varroavirus interaction in collapsing honey bee colonies. PLoS One 8(3), e57540

Frey, E., Rosenkranz, P. (2014) Autumn invasion rates of Varroa destructor (Mesostigmata: Varroidae) into honey bee (Hymenoptera: Apidae) colonies and the resulting increase in mite populations. J. Econ. Entomol. 107, 508-515

Frey, E., Odemer, R., Blum, T., Rosenkranz, P. (2013) Activation and interruption of the reproduction of Varroa destructor is triggered by host signals (Apis mellifera ). J. Invertebr. Pathol. 113, 56-62

Frost, E.H., Shutler, D., Hillier, N.K. (2013) Effects of fluvalinate on honey bee learning, memory, responsiveness to sucrose, and survival. J. Exp. Biol. 216, 2931-2938 
Gallai, N., Salles, J.-M., Settele, J., Vaissière, B.E. (2009) Economic valuation of the vulnerability of world agriculture confronted with pollinator decline. Ecol. Econ. 68, 810-821

Garbian, Y., Maori, E., Kalev, H., Shafir, S., Sela, I. (2012) Bidirectional transfer of RNAi between honey bee and Varroa destructor. Varroa gene silencing reduces Varroa population. PLoS Pathog. 8(12), e1003035

Garrido, C., Rosenkranz, P. (2003) The reproductive program of female Varroa destructor mites is triggered by its host, Apis mellifera. Exp. Appl. Acarol. 31, 269273

Giovenazzo, P., Dubreuil, P. (2011) Evaluation of spring organic treatments against Varroa destructor (Acari: Varroidae) in honey bee Apis mellifera (Hymenoptera: Apidae) colonies in eastern Canada. Exp. Appl. Acarol. 55, 65-76

Gong, Y., Pace, T.C.S., Castillo, C., Bohne, C., O'Neill, M.A., Plettner, E. (2009) Ligandinteraction kinetics of the pheromone-binding protein from the gypsy moth, L. dispar: insights into the mechanism of binding and release. Chem. Biol. 16, 162-172

González-Cabrera, J., Davies, T.G.E., Field, L.M., Kennedy, P.J., Williamson, M.S. (2013) An amino acid substitution (L925V) associated with resistance to pyrethroids in Varroa destructor. PLoS One 8(12), e82941

Guarna, M.M., Melathopoulos, A.P., Huxter, E., Iovinella, I., Parker, R., et al. (2015) A search for protein biomarkers links olfactory signal transduction to social immunity. BMC Genomics 16, 63-79

Guzmán-Novoa, E., Eccles, L., Calvete, Y., McGowan, J., Kelly, P.G., Correa-Benítez, A. (2010) Varroa destructor is the main culprit for the death and reduced populations of overwintered honey bee (Apis mellifera) colonies in Ontario, Canada. Apidologie 41, 443-450

Hamiduzzaman, M.M., Sinia, A., Guzman-Novoa, E., Goodwin, P.H. (2012) Entomopathogenic fungi as potential biocontrol agents of the ecto-parasitic mite, Varroa destructor, and their effect on the immune response of honey bees (Apis mellifera L.). J. Invertebr. Pathol. 111, 237-243

Harris, J.W. (2015) Bees with Varroa Sensitive Hygiene preferentially remove mite infested pupae aged $\leq 5$ days post capping. J. Apic. Res. 46, 134-139

Häußermann, C.K., Ziegelmann, B., Bergmann, P., Rosenkranz, P. (2015) Male mites (Varroa destructor) perceive the female sex pheromone with the sensory pit organ on the front leg tarsi. Apidologie 46, 771778

Hillier, N.K., Frost, E.H., Shutler, D. (2013) Fate of dermally applied miticides fluvalinate and amitraz within honey bee (Hymenoptera: Apidae) bodies. J. Econ. Entomol. 106, 558-565

Honson, N.S., Gong, Y., Plettner, E., et al. (2005) Structure and function of insect odorant and pheromone-binding proteins (OBPs and PBPs) and chemosensory-specific proteins (CSPs). In: Chemical ecology and phytochemistry of forest ecosystems, 39th edn, pp. 227268. Elsevier Ltd, Oxford

Ibrahim, A., Reuter, G.S., Spivak, M. (2007) Field trial of honey bee colonies bred for mechanisms of resistance against Varroa destructor. Apidologie 38, 67-76

Imdorf, A., Bogdanov, S., Ochoa, R.I., Calderone, N.W. (1999) Use of essential oils for the control of Varroa jacobsoni Oud. in honey bee colonies. Apidologie 30, 209-228

Kain, P., Boyle, S.M., Tharadra, S.K., Guda, T., Pham, C., et al. (2013) Odour receptors and neurons for DEET and new insect repellents. Nature 502, 507-514

Keeling, C.I., Slessor, K.N., Higo, H.A., Winston, M.L. (2003) New components of the honey bee (Apis mellifera L.) queen retinue pheromone. Proc. Natl. Acad. Sci. 100 , 4486-4491

Keeling, C.I., Plettner, E., Slessor, K.N. (2004) Hymenopteran semiochemicals. Top. Curr. Chem., Pheromones Other Semiochemicals 239, 133-177

Kelber, C., Rossler, W., Kleineidam, C.J. (2006) Multiple olfactory receptor neurons and their axonal projections in the antennal lobe of the honeybee Apis mellifera. J. Comp. Neurol. 496, 395-405

Klein, A.-M., Vaissière, B.E., Cane, J.H., SteffanDewenter, I., Cunningham, S.A., et al. (2007) Importance of pollinators in changing landscapes for world crops. Proc. R. Soc. B 274, 303-313

Kuster, R.D., Boncristiani, H.F., Ruepell, O. (2014) Immunogene and viral transcript dynamics during parasitic Varroa destructor mite infection of developing honey bee (Apis mellifera) pupae. J. Exp. Biol. 217, 1710-1718

Le Conte, Y., Bécard, J.-M., Costagliola, G., deVaublanc, G., El Maataoui, M., et al. (2006) Larval salivary glands are a source of primer and releaser pheromone in honey bee (Apis mellifera L.). Naturwissenschaften 93, 237-41

Le Conte, Y., Ellis, M., Ritter, W. (2010) Varroa mites and honey bee health: can Varroa explain part of the colony losses? Apidologie 41, 353-363

Lindberg, C.M., Melathopoulos, A.P., Winston, M.L. (2000) Laboratory evaluation of miticides to control Varroa jacobsoni (Acari: Varroidae), a honey bee (Hymenoptera: Apidae) parasite. J. Econ. Entomol. 93, 189-198

Locke, B., Le Conte, Y., Crauser, D., Fries, I. (2012) Host adaptations reduce the reproductive success of Varroa destructor in two distinct European honey bee populations. Ecol. Evol. 2, 1144-1150

Lodesani, M., Costa, C., Besana, A., Dall'Olio, R., Franceschetti, S., Tesoriero, D., et al. (2014) Impact of control strategies for Varroa destructor on colony survival and health in northern and central regions of Italy. J. Apic. Res. 53 , 155-164

Maggi, M.D., Ruffinengo, S.R., Damiani, N., Sardella, N.H., Eguaras, M.J. (2009) First detection of Varroa 
destructor resistance to coumaphos in Argentina. Exp. Appl. Acarol. 47, 317-320

Maisonnasse, A., Lenoir, J.-C., Costagliola, G., Beslay, D., Choteau, F., et al. (2009) A scientific note on E- $\beta$ ocimene, a new volatile primer pheromone that inhibits worker ovary development in honey bees. Apidologie 40, 562-564

Maul, V., Klepsch, A., Assmann-Werthmüller, U. (1988) Das Bannwabenverfahren als Element Imkerlicher Betriebsweise bei Starkem Befall mit Varroa jacobsoni Oud. Apidologie 19, 139-154

Meikle, W., Sammataro, D., Neumann, P., Pflugfelder, J. (2012) Challenges for developing pathogen-based biopesticides against Varroa destructor (Mesostigmata: Varroidae). Apidologie 43, 501-14

Melathopoulos, A.P., Winston, M.L., Whittington, R., Higo, H., Doux, M.L. (2000) Field evaluation of Neem and Canola oil for the selective control of the honey bee (Hymenoptera: Apidae) mite parasites Varroa Jacobsoni (Acari: Varroidae) and Acarpis woodi (Acari: Tarsonemidae). J. Econ. Entomol. 93, 559-67

Mondet, F., Goodwin, M., Mercer, A. (2011) Age-related changes in the behavioural response of honeybees to Apiguard $囚$, a thymol-based treatment used to control the mite Varroa destructor. J. Comp. Physiol. A. 197, 1055-1062

Moritz, F.A., Erler, S. (2016) Lost colonies found in a data mine: global honey trade but not pests or pesticides as a major cause of regional honeybee colony declines. Agric. Ecosyst. Environ. 216, 44-50

Naug, D. (2009) Nutritional stress due to habitat loss may explain recent honeybee colony collapses. Biol. Conserv. 142, 2369-2372

Naumann, K., Isman, M.B. (1996) Toxicity of a Neem (Azadirachta indica A. Juss) insecticide to larval honey bees. Am Bee J 136, 518-520

Nazzi, F., Pennacchio, F. (2014) Disentangling multiple interactions in the hive ecosystem. Trends Parasitol. 30, 556-560

Nazzi, F., Milani, N., Vedova, G.D. (2004) A semiochemical from larval food influences the entrance of Varroa destructor into brood cells. Apidologie 35, 403-410

Nicodemo, D., Hong, D.D., Couto, R.H.N., Malheiros, E.B. (2013) Honey bee lines selected for high propolis production also have superior hygienic behavior and increased honey and pollen stores. Gen. Mol. Res. 12, 6931-6938

Pankiw, T., Winston, M.L., Plettner, E., Slessor, K.N., Pettis, J.S., Taylor, O.R. (1996) Mandibular gland components of European and Africanized honey bee queens (Apis mellifera L.). J. Chem. Ecol. 22, 605615

Parker, R., Guarna, M.M., Melathopoulos, A.P., Moon, K.M., White, R., et al. (2012) Correlation of proteomewide changes with social immunity behaviors provides insight into resistance to the parasitic mite, Varroa destructor, in the honey bee (Apis mellifera). Genome Biol. 13, R81

Pernal, S.F., Baird, D.S., Birmingham, A.L., Higo, H.A., Slessor, K.N., Winston, M.L. (2005) Semiochemicals influencing the host-finding behaviour of Varroa destructor. Exp. Appl. Acarol. 37, 1-26

Piccolo, F.D., Nazzi, F., Vedova, G.D., Milani, N. (2010) Selection of Apis mellifera workers by the parasitic mite Varroa destructor using host cuticular hydrocarbons. Parasitology 137, 967-973

Pietropaoli M., Mortarino M., Formato G. (2015) The nightmare before Christmas: first cases of thymol resistance in Varroa destructor. COLOSS 11th Annual Meeting, Slovenia, November 20-24

Pirali-Kheirabadi, K., Teixeira-da-Silva, J.A., RazzaghiAbyaneh, M., Nazemnia, M. (2013) A field experiment to assess the rate of infestation in honey bee populations of two Metarhizium anisopliae isolates on Varroa destructor (Acari: Mesostigmata). J. Arthropod-Borne Dis. 7, 15-22

Plettner, E., Slessor, K.N., Winston, M.L., Robinson, G.E., Page, R.E. (1993) Mandibular gland components and ovarian development as measures of caste differentiation in the honey bee (Apis mellifera L.). J. Insect Physiol. 39, 235-240

Plettner, E., Slessor, K.N., Winston, M.L., Oliver, J.E. (1996) Caste-selective pheromone biosynthesis in honeybees. Science 271, 1851-1853

Plettner, E., Otis, G.W., Wimalaratne, P.D.C., Winston, M.L., Slessor, K.N., Pankiw, T., Punchihewa, P.W.K. (1997) Species- and caste-determined mandibular gland signals in honeybees (Apis). J. Chem. Ecol. 23, 363-377

Rademacher, E., Harz, M. (2006) Oxalic acid for the control of varroosis in honey bee colonies - a review. Apidologie 37, 98-120

Rinderer, T.E., Danka, R.G., Johnson, S., Bourgeois, A.L., Frake, A.M., et al. (2014a) Functionality of Varroaresistant honey bees (Hymenoptera Apidae) when used for western U.S. honey production and almond pollination. J. Econ. Entomol. 107, 523-30

Rinderer, T.E., Guzman, L.I.D., Frake, A.M., Traver, M.R., Khongphinitbunjong, K. (2014b) An evaluation of the associations of parameters related to the fall of Varroa destructor (Acari: Varroidae) from commercial honey bee (Hymenoptera: Apidae) colonies as tools for selective breeding for mite resistance. J. Econ. Entomol. 107, 516-522

Rosenkranz, P., Tewarson, N.C., Singh, A., Engels, W. (1993) Differential hygienic behaviour towards Varroa jacobsoni in capped worker brood of Apis cerana depends on alien scent adhering to the mites. J. Apic. Res. 32, 89-93

Rosenkranz, P., Aumeier, P., Ziegelmann, B. (2010) Biology and control of Varroa destructor. J. Invertebr. Pathol. 103, S96-S119

Ryan, M.F. (2002) The chemoreceptive organs: structural aspects. Insect chemoreception: fundamental and applied, pp. 113-139. Springer, N. Y 
Samson-Robert, O., Labrie, G., Chagnon, M., Fournier, V. (2014) Neonicotinoid-contaminated puddles of water represent a risk of intoxication for honey bees. PLoS One 9(12), e108443

Schroeder, A., Fritz, B., Weber, K., Wallner, D. (2007) A bee repellent endangers the quality of bee products. Abstracts of Association of Institutes for Bee Research Report of the 54th seminar in Veitshöchheim 27-29 March 2007. Apidologie 38, 495-496

Simon-Delso, N., SanMartin, G., Bruneau, E., Minsart, L.A., Mouret, C., Hautier, L. (2014) Honeybee colony disorder in crop areas: the role of pesticides and viruses. PLoS One 9 (7), e103073

Singh, N.K., Eliash, N., Kamer, Y., Zaidman, I., Plettner, E., Soroker, V. (2014) The effect of DEET on chemosensing of the honey bee and its parasite Varroa destructor. Apidologie 46 (3), 380-391

Singh N.K., Eliash N., Pinnelli G.R., Kamer Y., Zaidman I., et al. (2015) Specific disruption of Varroa chemosensing. Proceedings of the $22^{\circ}$ Congreso Internacional De Actualización Apícola. Oaxaca, Mexico.

Singh, N.K., Eliash, N., Stein, I., Kamer, Y., Ilia, Z., Rafaeli, A., Soroker, V. (2016) Identification and gene-silencing of a putative odorant receptor transcription factor in Varroa destructor: possible role in olfaction. Insect Mol. Biol. 25, 181-190

Slessor, K.N., Kaminski, L.-A., King, G.G.S., Borden, J.H., Winston, M.L. (1988) Semiochemical basis of the retinue response to queen honey bees. Nature 332 , 354-356

Spivak, M., Masterman, R., Ross, R., Mesce, K.A. (2003) Hygienic behavior in the honey bee (Apis mellifera L.) and the modulatory role of octopamine. J. Neurobiol. 55, 341-54

Sponsler, D.B., Johnson, R.M. (2015) Honey bee success predicted by landscape composition in Ohio, USA. Peer J. . doi:10.7717/peerj.838

Swanson, J.A.I., Torto, B., Kells, S.A., Mesce, K.A., Tumlinson, J.H., Spivak, M. (2009) Odorants that induce hygienic behavior in honeybees: identification of volatile compounds in chalkbrood-infected honeybee larvae. J. Chem. Ecol. 35 , 1108-1116

Tewarson, N.C., Singh, A., Engels, W. (1992) Reproduction of Varroa jacobsoni in colonies of Apis cerana indica under natural and experimental conditions. Apidologie 23, 161-171

Tsuruda, J.M., Harris, J.W., Bourgeois, L., Danka, R.G., Hunt, G.J. (2012) High-resolution linkage analyses to identify genes that influence Varroa sensitive hygiene behavior in honey bees. PLoS One 7(11), e48276

Wanner, K.W., Robertson, H.M. (2010) Lepidopteran chemoreceptors. In: Goldsmith, M.R., Marec, F. (eds.) Molecular biology and genetics of the Lepidoptera. CRC Press, Boca Raton

Wanner, K.W., Nichols, A.S., Walden, K.K.O., Brockmann, A., Luetje, C.W., Robertson, H.M. (2007) A honey bee odorant receptor for the queen substance 9-oxo-2-decenoic acid. Proc. Natl. Acad. Sci. 104, 14383-14388

Wantuch, H.A., Tarpy, D.R. (2009) Removal of drone brood from Apis mellifera (Hymenoptera: Apidae) colonies to control Varroa destructor (Acari: Varroidae) and retain adult drones. J. Econ. Entomol. 102, 2033-2040

Williams, I.H., Pickett, J.A., Martin, A.P. (1981) The Nasonov pheromone of the honeybee Apis mellifera L. (Hymenoptera, Apidae). Part II. Bioassay of the components using foragers. J. Chem. Ecol. 7, 225-237

Wolf, S., McMahon, D.P., Lim, K.S., Pull, C.D., Clark, S.J., Paxton, R.J., et al. (2014) So near and yet so far: harmonic radar reveals reduced homing ability of Nosema infected honeybees. PLoS One 9 (8), e103989

Ziegelmann, B., Rosenkranz, P. (2014) Mating disruption of the honeybee mite Varroa destructor under laboratory and field conditions. Chemoecology 24, 137-144

Ziegelmann, B., Lindenmayer, A., Steidle, J., Rosenkranz, P. (2013a) The mating behavior of Varroa destructor is triggered by a female sex pheromone. Part 1: preference behavior of male mites in a laboratory bioassay. Apidologie 44, 314-23

Ziegelmann, B., Tolasch, T., Steidle, J.L.M., Rosenkranz, P. (2013b) The mating behavior of Varroa destructor is triggered by a female sex pheromone. Part 2: identification and dose-dependent effects of components of the Varroa sex pheromone. Apidologie 44, 481-490

Zufall, F., Stengl, M., Franke, C., Hildebrand, J.G., Hatt, H. (1991) Ionic currents of cultured olfactory receptor neurons from antennae of male Manduca sexta. J. Neurosci. 11, 956-965 